\title{
Optical tweezer system with no fluorescent confocal microscope for trapping colloidal nanoparticles
}

\author{
${ }^{1}$ R. Nuansri, ${ }^{1}$ P. Buranasiri, ${ }^{1,2}$ P. Limsuwan and ${ }^{3}$ H.D. Ou-Yang \\ ${ }^{1}$ Department of Physics, Faculty of Science, King Mongkut's Institute of \\ Technology Ladkrabang, Bangkok 10520, Thailand, opticslaser@yahoo.com \\ ${ }^{2}$ Department of Physics, Faculty of Science, King Mongkut's University of \\ Technology Thonburi, Bangkok 10140, Thailand \\ ${ }^{3}$ Department of Physics, Lehigh University, Bethlehem, Pennsylvania 18015, USA, \\ hdo0@lehigh.edu
}

Received: 28.05 .2018

\begin{abstract}
We describe two optical tweezer systems for the studies of laser trapping of fluorescent colloidal nanoparticles (NPs). The first one, conventional optical tweezer system widely used in laser trapping, requires a fluorescent confocal microscope for observing trapped NPs. The second system, with no microscope, is presented for the first time in this work. The quantity of trapped NPs for this system is estimated from the transmitted laser light intensity that passes through the fluorescent colloidal NPs. Then the transmitted laser light is converted into the voltage signal and measured by an oscilloscope. A small capillary tube to be filled by the colloidal NPs is developed and used in the second system. This tube can be used with light-sensitive cameras for which a danger of damaging by high light intensities exists. Finally, we show that the results obtained using the both tweezer systems are in good agreement.
\end{abstract}

Keywords: optical tweezers, laser trapping, fluorescent particles, pluronic polymers

PACS: $42.66 .-\mathrm{V}$

UDC: 535.214

\section{Introduction}

In the recent years, many researchers have been interested in the techniques aimed at investigating, manipulating, trapping and even confining micro- and nanoparticles (NPs) in suspensions and biological cells. There are many important techniques used for trapping or manipulating these objects in various fields of science. These are dielectrophoretic tweezer [1], acoustic tweezer [2], magnetic tweezer [3], hydrodynamic trapping with microfluidic valving [4], optical tweezer and laser trapping [5]. Each of these techniques is suitable for different research areas and has its particular advantages or drawbacks that determine proper applications.

Optical tweezers represent a well-known technique ever since A. Ashkin has discovered acceleration and trapping of particles by radiation pressure in 1970 [6]. The approach has become a significant tool for frapping particles, which resembles a scissor or a tweezer. The technique can be used for various objects, e.g. trapping single micro-particles [5-7], simultaneously confining multiple NPs [8-12], studying chromosome movements [13], and recent approaches for trapping red blood cells in living animals [14] in tightly focused laser beams. In order to trap multiple NPs, many parameters of trapped particles have been studied, including those defining the interactions between colloidal particles $[15,16]$, the properties and the interactions of particles surrounded by absorbing [17] or non-absorbing [18] polymers, and the properties of colloidal particle surfaces in suspensions. 
In connection with numerous applications of optical tweezers in different areas, we have suggested aт optical tweezer device to be attached to the light-sensitive camera lenses for which there is a danger of damaging from a sudden and high intensities of light exposed at the camera. If a high-intensity light exposes the camera lenses, some colloidal NPs in the device behave as a part of the camera lens. Then the device should cause the colloidal NPs to aggregate quickly and dissipate the light before it damages the camera lenses.

In the present work, we build and describe the two following optical tweezer systems for trapping colloidal NPs in suspension: (1) a system with a fluorescent confocal microscope and (2) a system with no fluorescent confocal microscope. The second optical tweezer is suggested for the first time. In addition, we develop and use in the second system a small capillary tube to be filled with the colloidal NPs. This capillary tube is aimed to be used with the light-sensitive cameras that can be damaged by high intensities.

\section{Theory}

\subsection{Optical forces acting on nanospherical particles}

When a radiation pressure from a laser beam is used for trapping particles, there are two force components that act on these particles. The first component is a trapping optical gradient force of a laser which acts perpendicular to the direction of light propagation. The other one is a scattering force directed along the direction of laser light propagation. When trapping a nanospherical particle of which size is much smaller than the light wavelength of a trapping laser, one can assume that the NP represents a simple dipole [19]. The particles are pulled towards the focus of laser beam by the optical gradient force and, at the same time, they are pushed away from the focus by the scattering force. If small particles need to be confined in a trap in an easy and stable manner, the optical gradient force must be large enough if compared to the light scattering force due to momentum transfer of electromagnetic wave. The intensity of trapping laser is required to be high enough in order to overcome the effect of Brownian motion $[8,9]$. Furthermore, by using the objective lens with high numerical apertures, one can focus the laser beam tightly [20]. Finally, when confining multiple particles simultaneously at a focal point, one has to consider particleparticle and particle-light interactions. This is unlike the case of trapping of a single microparticle, where only the effect of laser trapping on a particle is relevant [8].

As a result, for the optical tweezer system without microscope, the optical gradient force of the laser is weak compared to the scattering force and the thermal effect from the Brownian motion. This leads to forward movement of NPs along the direction of laser light propagation. Hence, the colloidal NPs in the suspension are added to polymers in order to decrease the effect of the Brownian motion. This is described in Section 2.

\subsection{Interaction of colloidal particles with polymers}

In this work, polystyrene (PS), a pluronic polymer, and poly-ethylene glycol (PEG) are used when preparing the solution of colloidal particles for investigations of the laser trapping. Therefore the interaction of colloidal particles with the polymers should be discussed.

Usually, the colloidal particles suspended in an aqueous solution carry positive charges around their surface more than negative ones. Fig. 1a shows the PS colloidal particles suspended in an aqueous solution and mixed with PEG, which represents a non-absorbing polymer. There is some aggregation of the particles in the suspension. If the PS colloidal particles are mixed with the pluronic polymer (a so-called PEG-PPG-PEG triblock - see Fig. 1b), the middle PPG section which is hydrophobic is chain-anchored on a spherical surface, while the two PEG sides of the

Ukr. J. Phys. Opt. 2018, Volume 19, Issue 3 


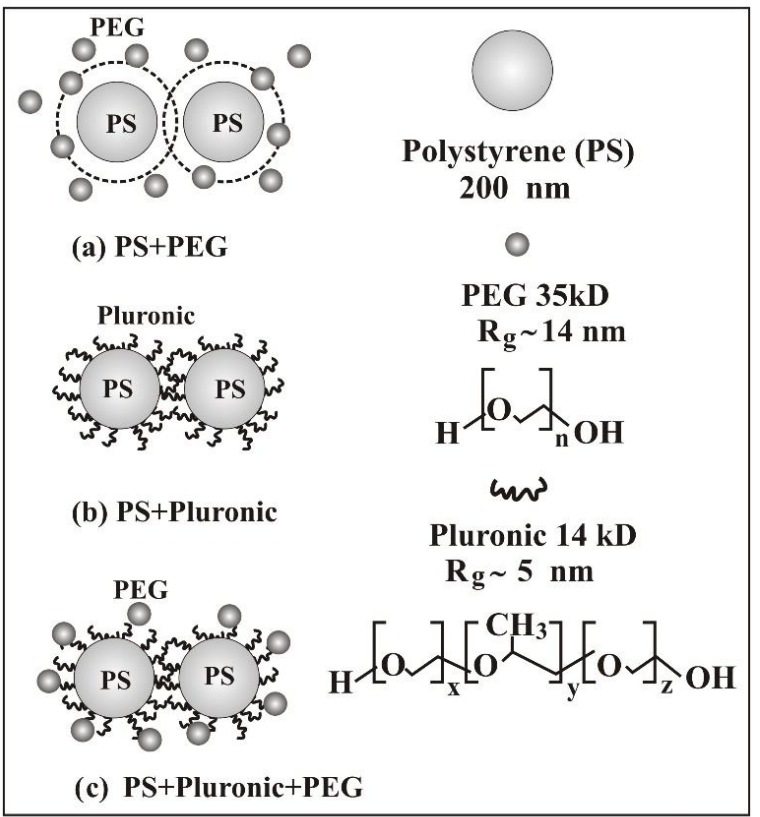

Fig. 1. Schemes of PS particles surrounded by PEG polymer (a), pluronic polymer (b) and pluronic polymer with PEG polymer (c).

pluronic polymer are like brushes in an aqueous environment [17]. These brushes generate a repulsive force that prevents aggregation due to particle interactions. In order to enhance the attractive force acting among the particles coated by the pluronic polymer in solution, a non-absorbing PEG polymer with neutral long chains is added to the solution, as shown in Fig. 1c. The brushes of pluronic coated on the PS surface can be bound, along with crowding PEGs, as described previously in Ref. [21]. The size of the polymers is characterized by a so-called gyration radius $R_{g}$. The $R_{g}$ parameters of $14 \mathrm{kD}$ pluronic and $35 \mathrm{kD}$ PEG are about 5 and $14 \mathrm{~nm}$, respectively.

To increase the force of attraction among the particles in some other way, a potassium chloride $\mathrm{KCl}$ can be added to the suspension. Then the negative charges of the salt $\left(\mathrm{Cl}^{-}\right)$interact with the positive charges around the particles as mentioned above and become move closer to each other due to the attractive force. If one applies the colloidal suspension for trapping multiple particles by a focused laser, the repulsive and attractive forces among the particles generated in the presence of polymers are helpful. While the colloidal particles are trapped in a focused laser beam, many particles can move closer in a trap. This is caused by the effect of binding that appears between the pluronic and PEG chains. In addition, the repulsive force renders stability of the solution when there is no light acting on it.

\section{Experimental procedures}

\subsection{Material and sample preparations}

1.0 wt. \% aqueous fluorescent microsphere suspension made of the PS and dyed with a green fluorescent dye (Thermo Scientific) was used as a starting solution for the laser trapping. The particles of the fluorescent microsphere suspension had spherical shapes, with a diameter of $200 \mathrm{~nm}$. $50 \mu \mathrm{l}$ of a dyed PS aqueous solution was added to $12 \mu \mathrm{l}$ of the pluronic polymer (SigmaAldrich) with the volume concentration 1\%. Since the PS NP surfaces were coated by the pluronic polymer, the mixed solution was shaken in order to protect aggregation of the NPs. A potassium 
chloride $\mathrm{KCl}(100 \mathrm{mM} 12 \mu \mathrm{l}$; Sigma-Aldrich) was added to the solution to make the NPs move close to each other and to increase the attractive force among the NPs. To make the NPs hold each other well in the suspension, we added PEG (10\% by volume; Sigma-Aldrich) of seven different volumes $(10,20,30,40,45,50$ and $60 \mu \mathrm{l})$ and shaken the solution once again. All the samples were prepared immediately prior to their use as a suspension of colloidal NPs for laser trapping, because they could not be stable for a long enough time. The samples thus prepared were denoted as \#1 to \#7 (see Table 1). Finally, the sample \#8 referred to a pure dyed PS solution.

Table 1. Compositions of materials used for preparing our colloidal NP samples.

\begin{tabular}{|c|c|c|c|c|c|c|c|}
\hline \multirow{2}{*}{$\begin{array}{c}\text { Sample } \\
\#\end{array}$} & \multicolumn{4}{|c|}{ Volume of materials, $\mu \mathrm{l}$} & \multirow{2}{*}{$\begin{array}{c}\text { Total } \\
\text { volume, } \mu \mathrm{l}\end{array}$} & \multicolumn{2}{|c|}{ Volume fraction, ø } \\
\hline & $\begin{array}{l}\text { Dyed PS } \\
1 \% \mathrm{w} / \mathrm{w}\end{array}$ & $\begin{array}{c}\text { Pluronic } \\
1 \% \mathrm{v} / \mathrm{v}\end{array}$ & $\begin{array}{c}\mathrm{KCl} \\
100 \mathrm{mM}\end{array}$ & $\begin{array}{c}\text { PEG } \\
10 \% \mathrm{v} / \mathrm{v}\end{array}$ & & Particles & PEG \\
\hline 1 & 50 & 12 & 12 & 10 & 84 & 0.60 & 2.70 \\
\hline 2 & 50 & 12 & 12 & 20 & 94 & 0.53 & 4.83 \\
\hline 3 & 50 & 12 & 12 & 30 & 104 & 0.48 & 6.55 \\
\hline 4 & 50 & 12 & 12 & 40 & 114 & 0.44 & 7.96 \\
\hline 5 & 50 & 12 & 12 & 45 & 119 & 0.42 & 8.58 \\
\hline 6 & 50 & 12 & 12 & 50 & 124 & 0.40 & 9.15 \\
\hline 7 & 50 & 12 & 12 & 60 & 134 & 0.37 & 10.16 \\
\hline 8 & 50 & - & - & - & 50 & 1.00 & - \\
\hline
\end{tabular}

\subsection{Experimental}

In this work, two alternative optical tweezer systems are used for trapping the colloidal NPs in suspensions: (1) a conventional system with a fluorescent confocal microscope and (2) a novel system with no microscope.

Fig. 2 shows a schematic diagram of our optical tweezer system equipped with a fluorescent confocal microscope. This system is widely used to trap the particles [9]. $10 \mu \mathrm{l}$ of each of the samples \#1 to \#8 was sucked and dropped on a glass slide, and covered with a cover glass. It was placed under a fluorescent confocal microscope (Olympus, IX-81). A beam of a $1064 \mathrm{~nm} \mathrm{Nd:YAG}$ laser (Changchun New Industries Optoelectronics Tech.) with a maximum power $30 \mathrm{~mW}$ was used as a trapping beam. It was expanded by a beam expander $\mathrm{BE}_{1}$ and passed onto a half-wave plate denoted as $\lambda / 2$. This plate rotated the polarization direction of the laser beam so that its intensity

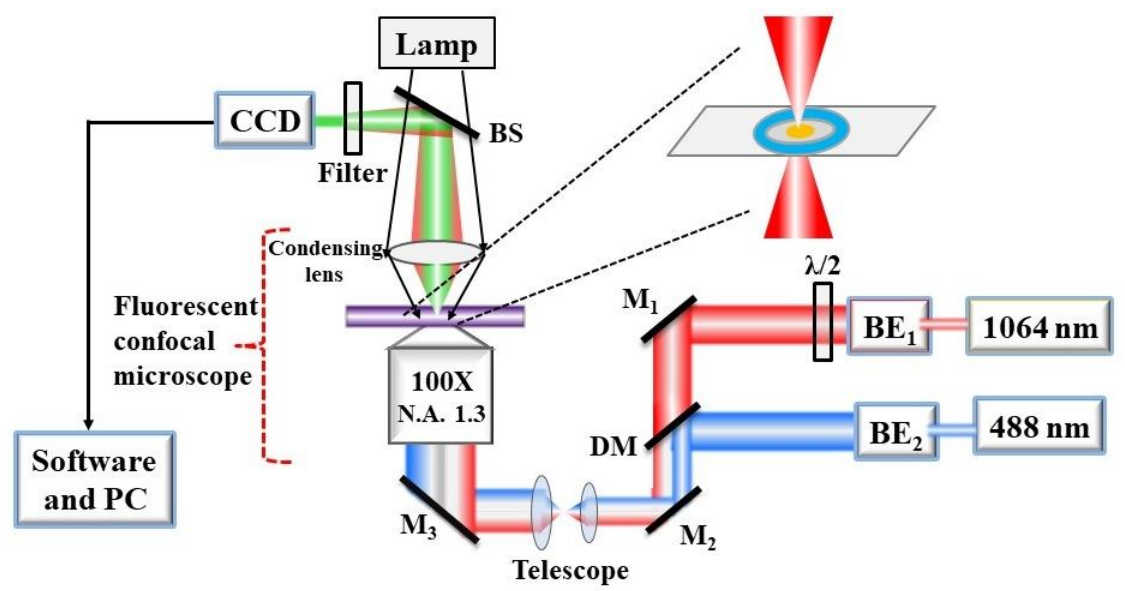

Fig. 2. Schematic diagram of our optical tweezer system built using a microscope with a 100X objective lens.

Ukr. J. Phys. Opt. 2018, Volume 19, Issue 3 
could be varied continuously. The $1064 \mathrm{~nm}$ laser beam of adjusted intensity was reflected by a mirror $\mathrm{M}_{1}$ and passed to a dichroic mirror (DM). At the same time, a blue beam emitted from an argon-ion laser at $488 \mathrm{~nm}$ (Showa Optronics, GLG3135) was allowed to pass through a beam expander $\mathrm{BE}_{2}$ and was reflected at the mirror DM. The $1064 \mathrm{~nm}$ laser beam could pass through the mirror DM, while the $488 \mathrm{~nm}$ beam was reflected by it. The both were reflected at a mirror $\mathrm{M}_{2}$ and collimated by a pair of telescope lenses. Then the beams were reflected at a mirror $\mathrm{M}_{3}$ to pass into an oil-immersion objective lens $(100 \mathrm{X}$, the numerical aperture 1.3; Olympus) in order to focus tightly the laser beams and obtain the laser-beam diameter $1 \mu \mathrm{m}$. The fluorescent colloidal NPs were trapped by the $1064 \mathrm{~nm}$ beam and excited by the $488 \mathrm{~nm}$ beam to emit a green fluorescent light at the wavelength of $508 \mathrm{~nm}$. The green fluorescent light of the trapped particles was collected by a condensing lens and reflected by a beam splitter BS. It passed through a filter and was recorded by a CCD camera with a resolution of 10 pixel per $1 \mu \mathrm{m}$. Then, the signal was monitored by software (Olympus, Fluoview FV 1000) and displayed on a computer monitor.

In case of our second optical tweezer system suggested for trapping the colloidal NPs, there is no confocal microscope and no objective lens, so that the laser beam is weakly focused. A scheme of this system is illustrated in Fig. 3. A diode-pumped Nd:YAG laser (Laserglow) with a doubled frequency $(532 \mathrm{~nm})$ was used as a light source. The laser light passed onto a variable filter for adjusting laser intensity. The optical density numbers of the filter can be varied from 3.0 to 0.08 in order to increase the output laser power from 0.370 to $374.100 \mathrm{~mW}$. This power was measured using a laser power meter with the resolution of 0.001 (Ophir Photonics, NOVA), which was connected behind the filter.

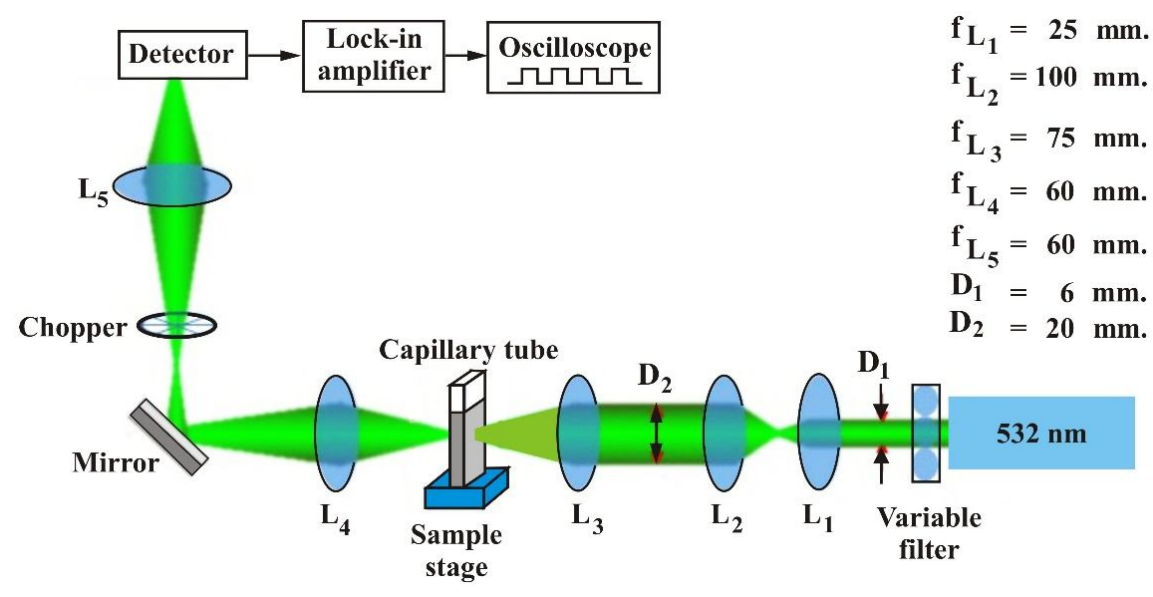

Fig. 3. Schematic diagram of our optical tweezer system built with no microscope. $L_{1}\left(f_{L_{1}}\right)$ to $L_{5}\left(f_{L_{5}}\right)$ denote lens and their focal lengths.

The laser beam with a diameter $\mathrm{D}_{1}(6 \mathrm{~mm})$ passed through a short focal-length lens $\mathrm{L}_{1}$ and was expanded to a diameter $\mathrm{D}_{2}(20 \mathrm{~mm})$ by a long focal-length lens $\mathrm{L}_{2}$. Then the laser beam was focused by a lens $\mathrm{L}_{3}$ to obtain a beam diameter of $1 \mathrm{~mm}$ and passed through the colloidal NPs filling a rectangular quartz capillary tube (Vitrocom Technical Glass). The dimensions of the capillary tube (width $\times$ length $\times$ height) were equal to $0.1 \times 2 \times 100 \mathrm{~mm}^{3}$. It was mounted on a sample stage in a vertical direction, where the side $2 \times 100 \mathrm{~mm}^{2}$ was perpendicular to the laser beam. In other words, the laser beam passed through the colloidal NPs with the thickness of $0.1 \mathrm{~mm}$ and trapped the NPs in the focused area. 
The transmitted light passed through a lens $\mathrm{L}_{4}$ and was chopped by an optical chopper to obtain a periodic light signal. This signal was focused by a lens $\mathrm{L}_{5}$ and detected with an optical detector. The detected signal was converted into a voltage signal and the signal-to-noise ratio was enhanced by a lock-in amplifier (Stanford Research, SR-830). Finally, the periodic voltage signal was monitored by an oscilloscope (Tektronix, TDS 2024).

\section{Results and discussion}

As seen from Fig. 2, the colloidal NPs in each sample mentioned in Table 1 fill the capillary tube. It is mounted on the sample stage at the focal point of the $100 \mathrm{X}$ objective lens under the fluorescent confocal microscope. Then the NPs are trapped by the $1064 \mathrm{~nm} \mathrm{Nd:YAG} \mathrm{laser} \mathrm{with}$ the power of $30 \mathrm{~mW}$. The trapped particles are observed through the eyepiece of the microscope and the fluorescent images are recorded with the CCD camera. Fig. 4 displays fluorescent images of the colloidal NPs.
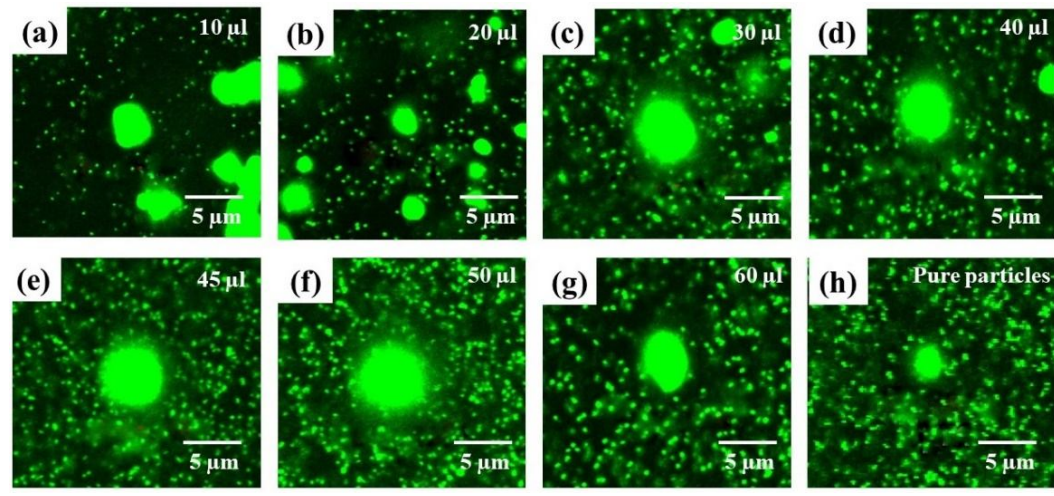

Fig. 4. Fluorescent images of colloidal NPs in the suspension trapped using the laser power of $30 \mathrm{~mW}$ at $1064 \mathrm{~nm}$ for different PEG contents: 10 (a), 20 (b), 30 (c), 40 (d), 45 (e), 50 (f) and $60 \mu \mathrm{l}$ (g). Panel (h) corresponds to the case when no PEG is used.

A bright green colour in Fig. 4 corresponds to the colloidal NPs suspended in the aqueous solution. This colour appears since the green fluorescent dye coated on the PS NPs is excited by the blue $488 \mathrm{~nm}$ laser and emits the green light at $508 \mathrm{~nm}$. There are multiply trapped particles confined simultaneously at the trapping area.

The images shown in Fig. 4a-d correspond respectively to the PEG contents 10, 20, 30 and $40 \mu 1$. Here many big bright-green lumps are observed, thus indicating that the colloidal NPs still aggregate themselves in the unstable solution. Therefore the particles cannot be confined steadily at the trapping area. When we add up to 45 and $50 \mu \mathrm{l}$ of PEG (samples \#5 and \#6), the particles are confined easily in the trap. The solution becomes stable, since there is no particle-particle aggregation (see Fig. 4e, f). Big trapped NPs are observed at the centre due to a high light intensity of the trapping laser and large attractive force acting among the particles, as described above. The solution is also stable in cases of the solution where $60 \mu \mathrm{l}$ of PEG is added (sample \#7) and the solution where no PEG is present (sample \#8). Nevertheless, the amount of the colloidal particles in the trapping area decreases. This results in decreasing numbers of the trapped particles, as seen from Fig. 4g, h. This fact is caused by a significant increase in the total volume of the solution, which results in decreasing volume fraction of the particles (see Table 1).

To confirm further the results presented in Fig. 4, we have repeated the experiments for each sample 10 times at the laser power of $30 \mathrm{~mW}$. In all the cases we have obtained the similar results. The diameter of the bright green circle seen from Fig. $4 \mathrm{f}$ has been repeatedly ( 5 times) determined 
using an ImageJ program. Then the average diameter of the trapped particles has been determined. It is equal to $5.89 \pm 0.26 \mu \mathrm{m}$.

As seen from Fig. 4, the sample \#6 with the PEG content equal to $50 \mu 1$ reveals the best laser trapping at the laser power of $30 \mathrm{~mW}$. Therefore, further experiments with this sample have been carried out for different laser powers $(5,10,15,20,25$ and $30 \mathrm{~mW})$. Fig. 5 shows the appropriate fluorescent images of the colloidal NPs in the suspension trapped by the laser. It is clearly seen that still more trapping of the colloidal NPs occurs beginning from $25 \mathrm{~mW}$ and at higher laser powers. Hence, one can conclude that the diameter of the particles trapped at the centre increases with increasing laser power.
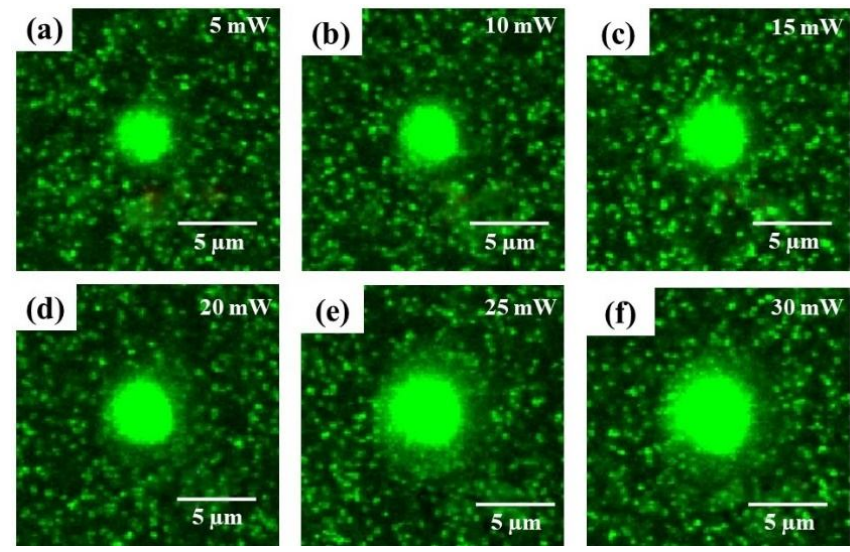

Fig. 5. Fluorescent images of trapped colloidal NPs in the suspension (sample \#6), as observed at different laser powers: 5 (a), 10 (b), 15 (c), 20 (d), 25 (e) and $30 \mathrm{~mW}$ (f).

We have also trapped the colloidal NPs for each of the samples mentioned in Table 1 using the $532 \mathrm{~nm}$ Nd:YAG laser (see the experimental setup displayed in Fig. 3). Here the output laser power has been changed by a variable filter, with the optical density numbers changing from 3.0 down to 0.08 . This corresponds to the output laser powers in the region $0.370-374.100 \mathrm{~mW}$. The transmitted light is finally converted into the voltage signal and measured by the oscilloscope. Fig. 6 shows the logarithm of the transmitted light measured in the units of electrical voltage as a function of optical density number, as obtained for the cases of colloidal NPs placed in the suspensions with different PEG contents $(10,20,30,40,45,50$ and $60 \mu 1)$. The dependences of the

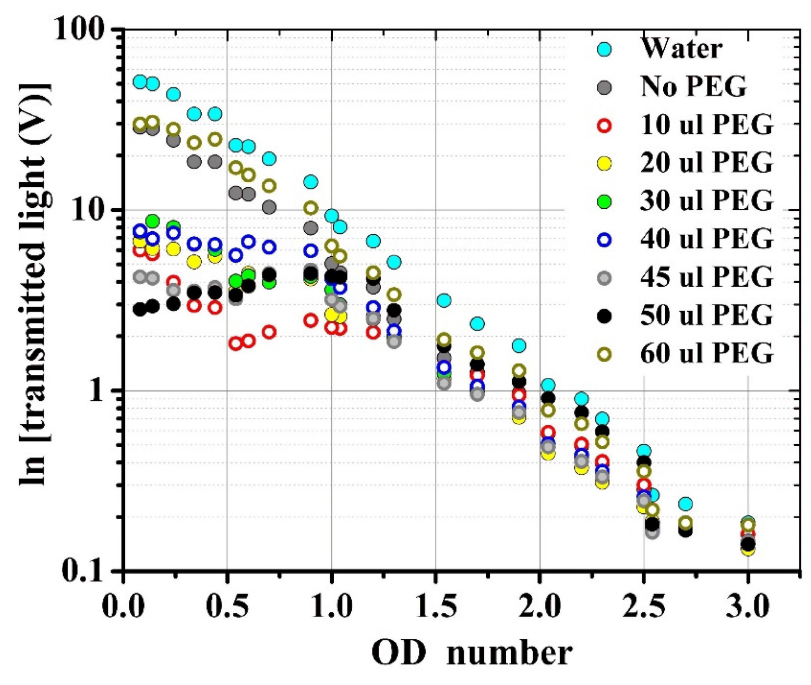

Fig. 6. Dependences of transmitted light intensity measured in the units of voltage logarithm on the optical power measured in the units of optical density (OD) number of filter, as measured for different PEG contents $(10,20,30,40,45,50$ and $60 \mu l)$, with water and with no PEG. 
voltage on the optical density number, which have been measured for the colloidal NPs with no PEG and with the pure water, are also shown in Fig. 6. It should be pointed out that the case of water has been studied for reference.

Our results demonstrate that, in the region of high optical density numbers (1.0-3.0) that corresponds to the region of low laser powers, the voltage changes linearly with the optical density number. This confirms that the colloidal NPs are not trapped in this region. When the optical density number decreases from 1.0 to 0.08 , the voltage tends to decrease due to increasing trapping of colloidal NPs. Furthermore, the sample \#6 with $50 \mu \mathrm{l}$ of PEG shows a smooth variation of the voltage, thus indicating stable trapping of the NPs under this condition.

Finally, we are to notice that the results obtained using the second optical tweezer system agree well with those obtained using a common confocal microscope system. However, our second system with no microscope is much more convenient for using as an optical tweezer and observing the trapping of colloidal NPs.

\section{Conclusion}

All of the optical tweezer systems used till now for laser trapping of the colloidal NPs have required a fluorescent confocal microscope for observing the trapped NPs. In this work, we have developed a novel optical tweezer system that does not make use of a fluorescent confocal microscope. In this system, the variable filter is used for adjusting the laser power while the colloidal NPs under study are filled in a rectangular capillary quartz tube with the dimensions of $0.1 \times 2 \times 100 \mathrm{~mm}^{3}$. The transmitted light that passes through the colloidal NPs is converted into a voltage signal and measured by an oscilloscope. Our system appears to be much more convenient when used for the observations of trapped NPs than the conventional optical tweezer systems.

\section{References}

1. Son M, Choi S, Ko H K, Kim H M, Lee S-Y, Key J, Yoon Y-R, Park I S and Lee S W, 2016. Characterization of the stiffness of multiple particles trapped by dielectrophoretic tweezers in a microfluidic device. Langmuir. 32: 922-927.

2. Yu Y, Qiu W, Chiu B and Sun L, 2015. Feasibility of multiple micro-particle trapping simulation study. Sensors. 15: 4958-4974.

3. Yan J, Skoko D and Marko J. F, 2004. Near-field magnetic tweezer manipulation of single DNA molecules. Phys. Rev. E. 70: 011905.

4. Zhou Y, Basu S, Wohlfahrt K J, Lee S F, Klenerman D, Laue E D and Seshia A A, 2016. A microfluidic platform for trapping, releasing and super-resolution imaging of single cells. Sensors Actuators B: Chem. 232: 680-691.

5. Ashkin A, Dziedzic J M, Bjorkholm J E and Chu S, 1986. Observation of a single-beam gradient force optical trap for dielectric particles. Opt. Lett. 11: 288-290.

6. Ashkin A, 1970. Acceleration and trapping of particles by radiation pressure. Phys. Rev. Lett. 24: $156-159$.

7. Wei M-T and Chiou A, 2005. Three-dimentional tracking of Brownian motion of a particle trapped in optical tweezers with a pair of orthogonal tracking beam and the determination of the associated optical force constants. Opt. Express. 13: 5798-5806.

8. Junio J, Ng J, Cohen J A, Lin Z F, and Ou-Yang H D, 2011. Ensemble method to measure the potential energy of nanoparticles in an optical trap. Opt. Lett. 36: 1497-1499.

9. Fu J, Zhan Q, Lim M Y, Li Z and Ou-Yang H D, 2013. Potential energy profile of colloidal nanoparticles in optical confinement. Opt. Lett. 38: 3995-3998. 
10. Ling L, Huang L, Fu J, Guo H, Li J, Ou-Yang H D and Li Z-Y, 2013. The properties of gold nanospheres studied with dark field optical trapping. Opt. Express. 21: 6618-6624.

11. Junio J, Park S, Kim M-W and Ou-Yang H D, 2010. Optical bottles: A quantitative analysis of optically confined nanoparticle ensembles in suspension. Solid State Commun. 150: 10031008.

12. Junio J, Cohen J A and Ou-Yang H D, 2016. Osmotic bulk modulus of charged colloids measured by ensemble optical trapping. J. Phys. Chem. B. 120: 9187-9194.

13. Berns M W, Wright W H, Tromberg B J, Profeta G A, Andrews J J and Walter R J, 1989. Use of a laser-induced optical force trap to study chromosome movement on the mitotic spindle. Proc. Natl. Acad. Sci. U. S. A. 86: 4539-4543.

14. Zhong M.-C, Wei X.-B, Zhou J.-H., Wang Z.-Q and Li Y.-M, 2013. Trapping red blood cells in living animals using optical tweezers. Nature Commun. 1768: 1-7.

15. Croker J C and Grier D G, 1994. Microscopic measurement of the pair interaction potential of charge-stabilized colloid. Phys. Rev. Lett. 73: 352-355.

16. Mellor C D, Sharp M A, Bain C D and Ward A D, 2005. Probing interactions between colloidal particles with oscillating optical tweezers. J. Appl. Phys. 97: 103114.

17. Li J-T, Caldwell K D and Rapoport N, 1994. Surface properties of pluronic-coated polymeric colloids. Langmuir. 10: 4475-4482.

18. Kim S Y and Zukoski C F, 2011. Role of polymer segment-Particle Surface Interactions in Controlling Nanoparticle Dispersions in Concentrated Polymer Solutions. Langmuir. 27: 10455- 10463.

19. Ashkin A, 1992. Forces of a single-beam gradient laser trap on a dielectric sphere in the ray optics regime. Biophys. J. 61: 569-582.

20. Harada Y and Asakura T, 1996. Radiation forces on a dielectric sphere in the Rayleigh scattering regime. Opt. Commun. 124: 529-541.

21. Fu J and Ou-Yang H D, 2014. Einstein's osmotic equilibrium of colloidal suspensions in conservative force fields. Proc. SPIE. 9164: $91641 \mathrm{~V}$.

R. Nuansri, P. Buranasiri, P. Limsuwan and H.D. Ou-Yang. 2018. Optical tweezer system with no fluorescent confocal microscope for trapping colloidal nanoparticles. Ukr.J.Phys.Opt. 19: 150 - 158. doi: $10.3116 / 16091833 / 19 / 3 / 150 / 2018$

Анотація. Описано дві системи оптичного пінцета для вивчення лазерного захоплення флуоресцентних колоїднх наночастинок (НЧ). Перша або звичайна система оптичного пінцета, яку широко застосовують для лазерного захоплення, вимагає флуоресцентного конфокального мікроскопа для спостереження захоплених НЧ. Другу систему без мікроскопа вперше представлено в иій роботі. Кількість захоплених НЧ для иієї системи оиінено з інтенсивності лазерного світла, яке проходить крізь флуоресцентні колоїдні НП. Далі пройдене лазерне світло перетворюється на сигнал напруги і вимірюється осцилографом. Для другої системи розроблено та використано невелику капілярну трубку, наповнену колоїдними НЧ. Цю трубку можна використовувати разом зі світлочутливими камерами, для яких є загроза пошкодження через високу інтенсивність світла. Нарешті, продемонстровано добре узгодження результатів, одержаних за допомогою обох систем пінцета. 